\title{
SOFTWARE PRODUCTS FOR THE NUMERIC EVALUATION OF OSCILLATION OF NOX IN THE PULVERIZED FUEL COMBUSTOR
}

\author{
E. A. Zueva ${ }^{1}, N$. V. Vizgavlyust ${ }^{1, *}, L$. V. Vorobyeva, and $A$. V. Starchenko ${ }^{2}$ \\ ${ }^{1}$ Tomsk Polytechnic University, 634050 Tomsk, Russia \\ ${ }^{2}$ Tomsk State University, 634050 Tomsk, Russia
}

\begin{abstract}
In this paper, a numerical study of the formation of nitrogen oxides in the combustion chamber based on the model created by Mitchellom and Terbellom. The distribution of furnace temperature and the concentration of nitrogen oxides, as well as a comparison of numerical results with the data of field experiment.
\end{abstract}

\section{Introduction}

One of most crucial problems occurring when organizing burning of fuel is the reduction of toxic substances generation, in particular nitrogen oxide. The requirements to air pollution control became more strict and they require elaborating some new approaches to designing of combustion equipment and chambers, and various power units $[1,2]$. At present time for the above purpose numerical simulation is often used which allows not only obtaining numerical evaluation of toxic emissions but developing recommendations on their reduction.

Of late numerous products appeared at the software market which can simulate and evaluate toxic emissions. The software differs regarding its price and accuracy of the final outcome.

The study is aimed to compare the software for numerical evaluation of nitrogen oxide generation when burning the solid fuel. The following software has been chosen for comparison. $\mathrm{NO}_{\mathrm{x}}$ and FIRE 3D-NO .

$\mathrm{NO}_{\mathrm{x}}$ software used for calculation of nitrogen oxide emissions is based on the technique of [3]. This software is one dimensional mathematical model. The results of calibration calculation of the boiler unit can be used as initial data for this software.

\footnotetext{
* Corresponding author: vizgavljust@,tpu.ru
} 


\section{Description of the model and the object of research}

The applied software of FIRE-3D-NO $\mathrm{N}_{\mathrm{x}}$ is a mathematical model, which task and kinetic scheme are presented in $[4,5]$.

The studied device was the combustion chamber of steam boiler of BKZ-320-140PT where Irsha-borodinsky coal from Kansk-Achinsk coal field is burnt. Steam boiler of BKZ$320-140-\mathrm{PT}$ is the unit with vertical water pipe with natural circulation of the flat top design. The combustion unit of the boiler is half open with fluid slag removal and consists of two interconnected eight-faced primary furnaces. Each of the primary furnaces is equipped with four straight flow two stage burners. Two discharge burners are located at the controlled zone (fig. 1).

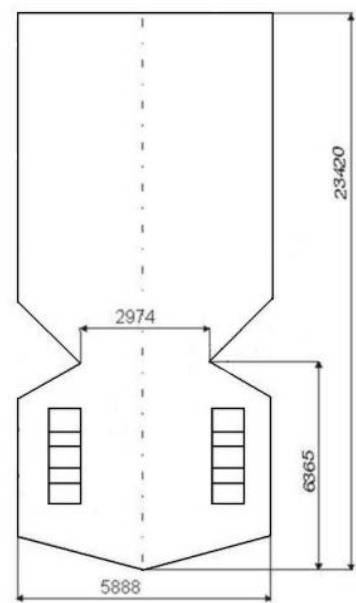

Fig. 1. Geometrical characteristics of the furnace of BKZ-320-140 boiler [6].

This boiler has been selected for the certain purpose. A number of engineering solutions aimed at the intra-furnace emissions inhibition have been implemented and tested in this boiler, which provided achieving the ultimate permissible level for the working boiler with furnace fluid slag removal [6].

\section{Results and discussion}

When working with the software the following techniques controlling nitrogen oxide emissions were selected: changes in steam capacity of the boiler and staged combustion of the solid fluid.

When changing the load of the boiler (D) within the ranges of 220-320 tons per hour the concentration of nitrogen oxide increases by $120 \mathrm{mg} / \mathrm{m}^{3}$ (fig. 2) due to the increase of the temperature level in the furnace chamber (the outlet furnace temperature changed from $1100^{\circ} \mathrm{C}$ to $1217^{\circ} \mathrm{C}$ ).

When changing the fuel distribution rate by staged combustion from 0.38 to 0.72 , the results of numerical testing and actual measurements are of fairly similar values (fig. 3 ). Increase of the fuel supply to the lower stage of this boiler unit is the best option to suppress the nitrogen oxide in the furnace: $\mathrm{NO}_{\mathrm{x}}$ decreases by $20 \%\left(100-150 \mathrm{mg} / \mathrm{m}^{3}\right)$.

The results of numerical simulation (fig. 2 and 3) have values fairly similar to the measurements and the qualitative parameters do not differ greatly. 


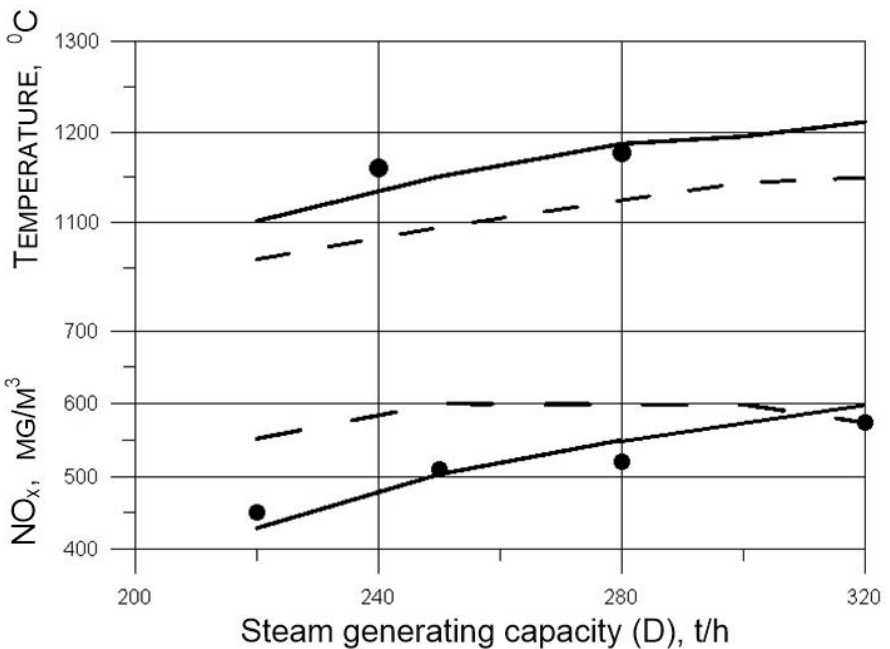

Fig. 2. Changes of the furnace outlet temperature and $\mathrm{NO}_{\mathrm{x}}$ concentration depending on the steam capacity: $\bullet-$ measurements [7], - - calculation with PPP FIRE 3D-NO $\mathrm{N}_{\mathrm{x}},---$ calculation as per technique [3].

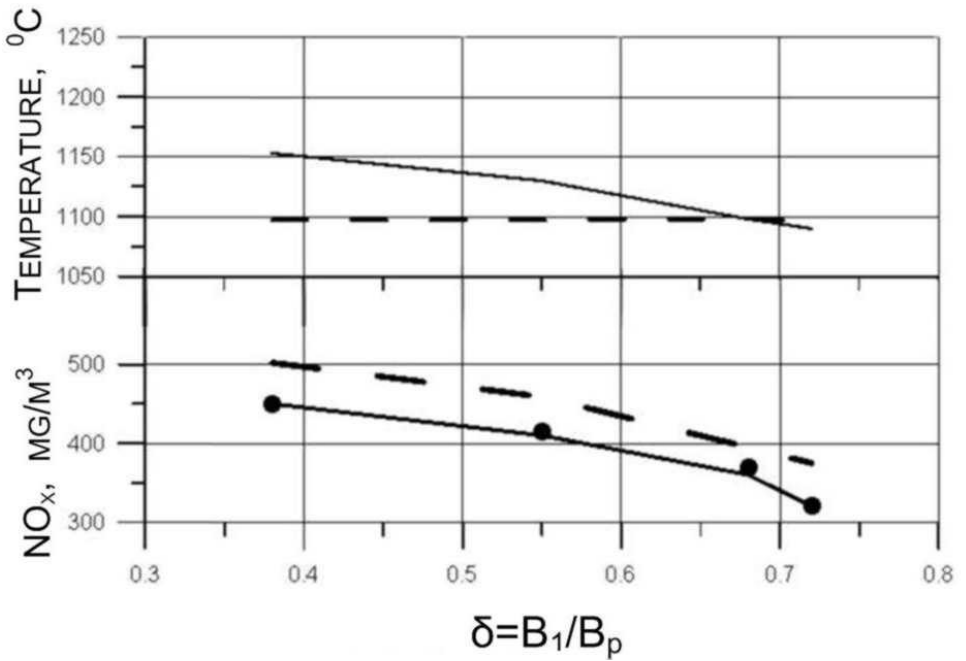

Fig. 3. Changes of the furnace outlet temperature and nitrogen oxide concentration depending on the staging of the fuel supply: $\bullet-$ measurements [7], - - calculation with PPP FIRE 3D-NO,- calculation as per technique [3]. 


\section{Conclusions}

The studied ranges of the capacity changes as in any boiler with fluid slag removal limited by temperature level providing the reliable discharge of the fluid slag demonstrates the fairly effective impact of the used means of nitrogen oxide generation inhibition and provides the basis for comparison with the other variable parameters of burning process.

The approach based on the staged combustion provides the temperature in the combustion area on the fairly high level and thus the regular fluid slag removal. Therefore unlike the other techniques it can be used for stabilization of emissions in the combination with changes in the boiler load thus compensating the generation of $\mathrm{NO}_{\mathrm{x}}$ when it increases.

Use of FIRE 3D- $\mathrm{NO}_{\mathrm{x}}$ software is an effective tool for forecasting the generation of nitrogen oxide in coal-dust furnaces of the boilers compared to $\mathrm{NO}_{\mathrm{x}}$ software which has been confirmed by the results of test numerical experiments demonstrating fairly good convergence with the data of actual measurements. FIRE 3D- $\mathrm{NO}_{x}$ software considers the information on the process of discharge and combustion of volatile fuel, aftercombustion of coke residue, to consider non-isothermality, turbulent diffusion and transfer of furnace medium components by the averaged motion, application of the developed model of NO formation when burning coal will allow to optimize process of combustion of dust-like fuel in package boilers of thermal power plants for increase of efficiency of burning out of fuel and reduction of emissions of $\mathrm{NO}_{\mathrm{x}}$.

\section{References}

1. Boiler units. Heat mechanical equipment. General technical requirements (State Standard R 50831-95)

2. V.R. Kotler, Nitrogen oxides in the flue gas boilers, (1987)

3. A.N. Bezgreshnov, Yu.M Lipov, Shleyfer B.M, Steam boiler calculations (1991)

4. J.W. Mitchell, J.M. Tarbell, AIChE Journal. 28 (1982)

5. N.V. Vizgavlyust, A.V. Starchenko, A.V. Gil, T.S. Taylasheva, EPJ Web Conf. 82 (2015)

6. O.I. Budilov, A.S. Zavorin, Experience to improve the environmental performance of the thermal power plant, (1994)

7. Study of the burning process on PK-39-2 boiler of 300MW of Yermakovskaya Hydro Power Station when burning ekibaztus coal by the direct injection scheme (Novosbirsk, 1975) 